técnicos de esta área aclaren y armonicen sus ideas. Por último se ha conseguido también llegar a acuerdos provechosos con el Programa de Inventario de Bienes Etnológicos iniciado este año.

Tales acuerdos hacen posible que en el futuro, Odiseus pueda acceder con facilidad a las bases de datos de estos otros programas utilizándolas como bases relacionales o de consulta y que a su vez, los programas desarrollados por estos otros proyectos puedan aprovechar sin dificultad la documentación elaborada por los museos.

Odiseus puede gestionar ahora no sólo la documentación sobre los fondos museográficos, sino que tiene capacidad para relacionarla, mientras la mantiene en pantalla, con el archivo administrativo del museo, con los repertorios de imagen y sonido o con los fondos de su biblioteca. Los programas que se ocupan de ello Museum, Papel, Sonimag y Leelo, integrados en el paquete Odiseus, pueden también arrancarse e instalarse por separado según las necesidades de cada usuario.

El Museo de Artes y Costumbres Populares está siendo utilizado como Centro Piloto de este Plan mientras que otros cuatro museos andaluces de distintas especialidades, parece que se sumarán a finales de este año al Proyecto Piloto con la instalación de Odiseus y la incorporación de becarios del Instituto Andaluz del Patrimonio para alimentar sus bases de datos.

Aun tomando en consideración los retrasos debidos a los avatares burocráticos, creemos que el próximo año estaremos en situación de comenzar a diseñar el funcionamiento en red de este programa. La utilidad de Odiseus crecerá a medida que las distintas especialidades de Museos vayan elaborando sistemas de clasificación de fondos y documentos, cada vez más pulidos, pues la relación de unas bases de datos con otras, descansa, fundamentalmente, en estos instrumentos de clasificación. Para mejorarlos, el paquete de programas incorpora una herramienta de construcción de thesaruos, que permite también modificar los ya construidos según las necesidades de cada especialidad.

A los que hemos trabajado en la elaboración del paquete Odiseus nos basta con la diversión de haberlo hecho, pero deseamos que el rigor y el pundonor con que del Instituto Andaluz del Patrimonio acogió esta iniciativa, termine dando resultados satisfactorios para todos.

\section{PATRIMONIO Y DESARROLLO}

Desarrollo sostenible, recursos endógenos, educación para la iniciativa, asociacionismo, participación ciudadana, autoempleo y economía social, desarrollo comarcal y local, calidad de vida, creatividad... Estos son algunos de los conceptos que vienen lentamente desarrollándose desde las últimas décadas y que van configurando, interrelacionados, un corpus ideológico con que afrontar el inicio del nuevo milenio.

Resulta que las democracias, tal como hoy las conocemos, y la economía de mercado o capitalismo, modelo económico sobre el que se sustentan, son un sistema político y económico con serios síntomas de agotamiento.

El modelo sustentado en la gran empresa capitalista, al igual que el comunista, no ha sido capaz de eliminar la pobreza de millones de personas y ha basado su productividad en la sobreexplotación y deterioro de los recursos naturales. Además, el uso masivo de alta tecnología, en su carrera por la competitividad, lleva aparejado el paro como problema estructural.

Por su parte, los grandes partidos políticos de corte tradicional y los sindicatos son estructuras cada vez más cerradas en sí mismas, mediante las que el ciudadano se siente insuficientemente representado. También el Estado y la Administración, como instrumentos que garantizan el bienestar social están amenazados en sus funciones por el déficit público, el crecimiento insuficiente, la reducción de la población activa, el aumento de las clases pasivas, su complejidad organizativa, etc.

Ante estos síntomas nuevas ideas comienzan a destacar. El concepto de Aldea Global nos lleva, por un lado, a entender la Tierra como una unidad frágil a proteger, pero también implica comprender la importancia de ese pequeño territorio: ciudad o comarca, heredado de nuestros antepasados y en el que se desenvuelve nuestra actividad diaria, cuyo uso incontrolado o abuso, puede embargar el futuro de generaciones venideras. La verdadera transformación que se preconiza desde el concepto de desarrollo sostenible es ideológica y profunda. Se trata de cambiar la visión actual de que la calidad de vida es sinónimo de consumo, o mejor dicho consumismo, mensaje continuo que difunden los medios de comunicación de masas, sostén de la economía de mercado.

No es serio pretender que los seis mil millones de habitantes de la Tierra consuman como occidentales sin arrasarla; ni obligar al resto del mundo a proteger los recursos naturales para que nosotros mantengamos nuestro nivel de vida a costa de su miseria.

Hay que revisar el modelo productivo y de sociedad a escala mundial. Mientras tanto, en las regiones periféricas de la CEE, como es el caso de Andalucía, algo está cambiando en este sentido. Hay un interés cada vez mayor en el desarrollo comarcal y local a partir de los recursos endógenos; esos en que la gran empresa no obtiene cuotas de beneficios extraordinarios pero que sí son capaces de mantener y emplear a un considerable número de población autóctona, desde fórmulas de economía social: autoempleo, cooperativismo, pequeña empresa, etc. Para el desarrollo local a partir de la explotación respetuosa del territorio es necesario por parte de sus habitantes un cambio de mentalidad que comienza por creérselo y continúa con la educación para la iniciativa, la participación activa de la población y la formación de técnicos para la gestión integral de recursos. Por parte de las Administraciones está el fomentar todas las iniciativas que se ajusten a un modelo de desarrollo coherente y proporcionado con sus recursos, capaces de elevar la calidad de vida de la población.

Desde esta perspectiva el Patrimonio, cultural y natural, es uno de los principales recursos endógenos para el desarrollo comarcal de Andalucía. Valorar culturalmente a un territorio es conocerlo, comprenderlo y 


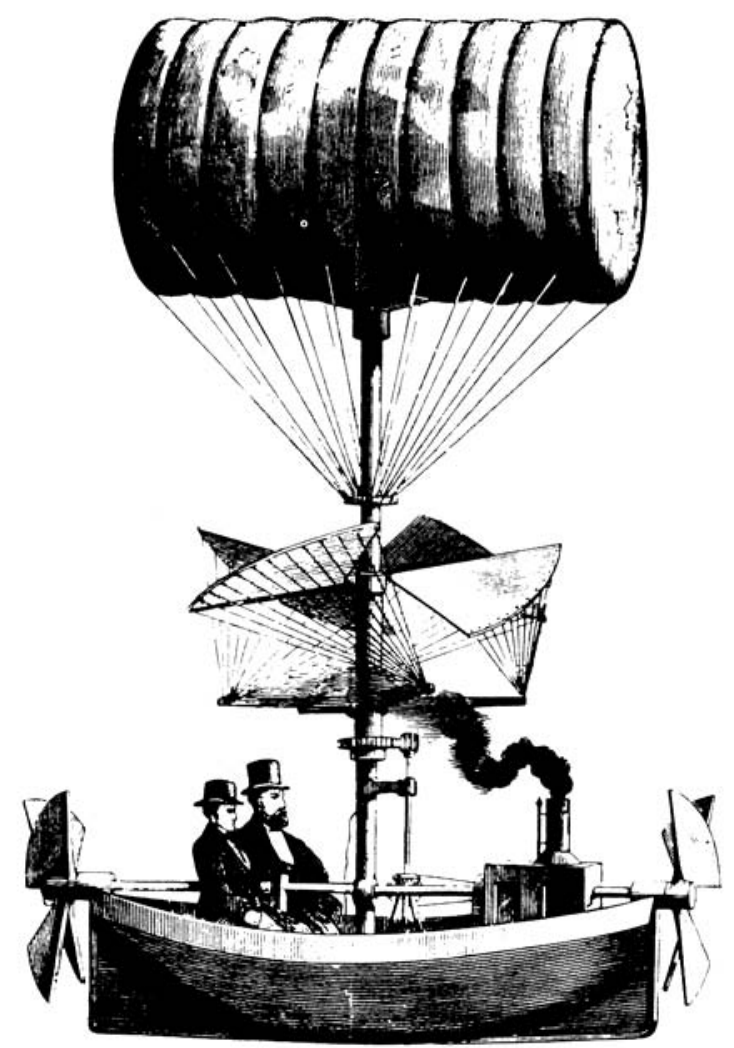

hacerlo propio respetándolo, también es poner de manifiesto la singularidad de sus recursos humanos y estimular la confianza de la sociedad en si misma y en su capacidad creativa. Valorar el Patrimonio como recurso económico y social es hablar de conservación, pero esta enmarcada en múltiples estrategias que confluyan en desarrollo.

El concepto genérico de Patrimonio, cultural y natural, tiene como dimensión la globalidad del territorio y sus habitantes. Su objetivo último es la calidad de vida, consecuencia de un desarrollo económico y social sostenible. Su metodología es la gestión integral a partir de estrategias territoriales.

Andalucía es una de las mayores regiones de Europa, con un territorio superior al de numerosos países. Su patrimonio natural es muy importante, con casi un millón y medio de hectáreas de espacios protegidos. Su patrimonio cultural, fruto de un intenso pasado, también: más de cien conjuntos históricos y multitud de monumentos y yacimientos arqueológicos y objetos artísticos. Su cultura viva tiene una originalidad inconfundible: música, danza, fiestas, manifestaciones religiosas, artesanías, etc. Su red de municipios está bien distribuida por el territorio sin graves problemas de despoblamiento.

Destruir, sobreexplotar o no aprovechar estas ventajas apostando por un modelo de desarrollo no respetuoso con el patrimonio cultural y natural es, hoy día, injustificable.

Aunque el turismo, $y$ en particular el turismo cultural, es una de las tradicionables fuentes de ingreso y empleo en Andalucía, esto apenas se ha traducido en una apuesta decidida por la conservación y presentación digna de nuestra historia y nuestras señas de identidad. Apostar por el turismo cultural es intentar mantener cuidadosamente el equilibrio entre el uso económico de los recursos culturales y al mismo tiempo acrecentarlos y conservarlos correctamente.
Para Frans Shouten el esquema conceptual del desarrollo sostenible, referido al medio ambiente natural, es por extensión válido a los aspectos culturales que están sometidos en muchos casos bajo las mismas presiones: la urbanización, los rápidos cambios de las infraestructuras, la introducción incontrolada de tecnología moderna, la sobreexplotación y eclosión del turismo, etc. Para dicho autor el turismo cultural, desde el punto de vista del desarrollo sostenible, representa el equilibrio entre la calidad de la experiencia del visitante, la calidad de los recursos culturales y su presentación y la calidad de vida de la población que los detenta.

La calidad de los recursos depende del modo en que estos sean usados como un valor económico. Un patrimonio sin uso difícilmente incentivará a la inversión para su conservación. Pero también hay que tener en cuenta que el Patrimonio es parte del ambiente de la actividad humana y es necesario integrarlo en la sociedad y proporcionarle la infraestructura necesaria para conservarlo y presentarlo.

La actividad turística debe mejorar la calidad de vida. La población local debe ser capaz de obtener beneficios económicos de esta actividad mediante empleo y negocio. La finalidad del desarrollo cultural sostenible y del turismo cultural basado en este concepto es la continuidad de nuestro pasado en el futuro. Los recursos patrimoniales deben ser mejorados para beneficio del mismo patrimonio, de aquellos que viven de él y con él, y de aquellos que son atraídos por éste.

En este sentido es de gran interés el Programa LEADER para el Desarrollo Comarcal financiado por los Fondos Estructurales FEDER, FSE y FEOGA, que desde 1991 viene funcionado en las comarcas andaluzas de la Axarquía de Málaga, Sierra de Cádiz, Sub-Bética, Alpujarra, Sierra Norte de Sevilla, Cuenca Minera de Río Tinto, Sierra Sur de Sevilla, la Loma de Jaén y Serranía de Ronda.

Este programa, a largo plazo, puede revertirse en un sistema comarcal de desarrollo rural a partir de recursos endógenos, que nace de la capacidad asociativa de los actores locales y con fuerte incidencia en el patrimonio natural y cultural. También va a permitir la puesta a punto de numerosos gestores comarcales con buena preparación en temas que comporten iniciativa y riesgo. Estos recursos humanos pueden ser decisivos en el futuro rural de Andalucía.

En resumen, hoy es imposible poner en duda el valor educativo, artístico, estético y de disfrute social del Patrimonio, pero también es indudable que los conceptos de riqueza y beneficio prevalecen en gran parte de una sociedad que ha entronizado el consumo material. Por todo ello resulta apropiado insistir en la importancia del Patrimonio también como generador de riqueza y así incluir su conservación desde esta actualización del discurso.

Deberíamos superar el peligros matiz de la disociación entre lo que la mayoría entiende por desarrollo, referido a las clásicas actividades consideradas productivas: agricultura, pesca, industria y comercio y el Patrimonio, natural e histórico, como elemento a proteger, es decir, como elemento controlador y obstaculizador del desarrollo no como desarrollo en sí mismo. Una disociación que sigue prevaleciendo en políticas desarrollistas que consideran "residual" la actividad cultural referida al patrimonio, como si el trabajo, las obras públicas y hasta la salud de una comunidad pudieran estar desvinculadas de su pasado, de sus tradiciones, en suma, de su propia identidad.

Al hablar desde el Patrimonio de temas como el empleo, la rentabilidad económica, el turismo, la calidad de vida,... es decir de la problemática socioeconómica que preocupa a la sociedad actual, reivindicamos para el Patrimonio el de ser también un sector productivo a tener en cuenta.

Carlos Romero Moragas Seminario Permanente de Patrimonio y Desarrollo 